Proceedings

\title{
Community Lead Awareness Partnership (CLAP) for Healthy Kids
}

\author{
Amal K. Mitra * and Charkarra Anderson-Lewis
}

* Correspondence: amal.k.mitra@jsums.edu

\begin{abstract}
The primary objectives of the project were to encourage health promotion through education, outreach and community based training and to support infrastructure development for the sustainability of lead prevention efforts. Methods: The study was conducted in Forrest County, Hattiesburg, Mississippi. CLAP staff distributed material and spoke at a wide variety of venues making over 50 public appearances at health fairs, schools, neighborhood meetings, community events and the local park. The number of participants were as follows: health fairs $(n=467)$, community events $(n=469)$, and Kindergarten classes $(n=241)$. Hands-on training was offered at homebuilding retail stores $(n=25)$. EPA/HUD's online visual training was given to realtors $(n=220)$, and inspectors, contractors, and Do-It-Yourself (DIY) workers $(n=75)$. Training workshops were attended by home-buyers and rental home owners at the Neighborhood Association Meetings $(n=$ 91). Impact of training was evaluated by pre- and posttests. Results: Hands-on Training: Nearly $90 \%$ of the participants $(n=25)$ reported the hands-on training was useful. EPA/HUD Online Training: At posttest, $59.4 \%, 67.9 \%, 65.1 \%$ of the participants $(n=220)$ identified soil, car batteries and paint as sources of lead in the environment, respectively. Nearly $70 \%$ identified lead as a poison in the environment while $77.5 \%$ and $47.2 \%$ of those surveyed demonstrated two different behaviors which will help prevent lead poisoning. A total of $62.3 \%, 48.1 \%$ and $58.5 \%$, at posttest, identified three complications (mental, physical and psychological) respectively. The mean posttest score was significantly higher than the pretest scores $(7.47 \pm 2.07$ vs. $6.60 \pm 1.68$, respectively. All the participants at a 2-month follow-up reported that that they used information obtained during the training on EPA-HUD curriculum on lead. The outcome measurements of home-buyer workshops were not significantly different from those of the online training. Conclusion: This training activities were successful in improving knowledge of the community people on lead poisoning prevention. Community programs are essential to ensure primary prevention of lead poisoning.
\end{abstract}

Publisher's Note: MDPI stays neutral with regard to jurisdictional claims in published maps and institutional affiliations.

\section{(c) (i)}

Copyright: (c) 2020 by the authors. Submitted for possible open access publication under the terms and conditions of the Creative Commons Attribution (CC BY) license (http://creativecommons.org/licenses /by/4.0/).
Keywords: Lead poisoning; training; prevention; outreach; Mississippi; EPA. 